\title{
A ESCOLA PRIMÁRIA TEUTO-BRASILEIRA RURAL: EDUCAÇÃO E SINCRETISMO EM SANTA CATARINA
}

\section{The rural German-Brazilian primary school: education and sincretism in Santa Catarina}

\author{
Ademir Valdir dos SANTOS \\ Universidade Federal de Santa Catarina \\ Correo-e: ademir.santos@ufsc.br
}

Recepción: 6 de junio de 20I9. Envío a informantes: 8 de junio de 2019

Aceptación definitiva: 20 de junio de 2019

Resumo: Objetiva analisar a origem da escola primária teuto-brasileira rural em Santa Catarina e sua instituição nas primeiras décadas do século xx. A metodologia é embasada na pesquisa documental, usando relatório, estatutos, termos de inspeção, estatísticas, livro, cadernos e fotografias. As análises são pautadas por bibliografia que aborda relações entre a educação e a imigração teuta. $\mathrm{O}$ exame das transformações por que passaram as escolas fundadas pelos imigrantes alemães em Santa Catarina mostra que, inicialmente, elas foram constituídas como escolas alemãs. Mas devido às modificações econômicas, políticas e socioculturais das primeiras décadas do século xx, construíram uma nova identidade, que amalgamou à germanidade elementos tipicamente brasileiros. Os resultados mostram que a escola primária teuto-brasileira rural é expressão de sincretismo, sendo originada do amálgama entre os dados germânicos trazidos com a imigração e as componentes culturais brasileiras.

Palavras-Chave: sincretismo; instituições educativas brasileiras; Santa Catarina.

AвstRact: It aims to analyze the rural Teutonic-Brazilian primary school in Santa Catarina and its institution in the first decades of the twentieth century. The methodology is based on documentary research, using report, statutes, inspection terms, statistics, book, exercise books and photographs. Analyzes are based on a bibliography that deals with the relationship between education and immigration. The examination of the transformations undergone by the German immigrant schools in Santa Catarina shows that, initially, they were constituted as German schools. But 
because of the economic, political and socio-cultural changes of the first decades of the twentieth century, they built a new identity, which amalgamated typically Brazilian elements with Germanism. The results show that the rural Teutonic-Brazilian primary school is an expression of syncretism, originated from the fusion of the German data brought with immigration and the Brazilian cultural components.

KEY wORDs: syncretism; educational institutions in Brazil; Santa Catarina.

\section{Introdução}

A vertente de investigação denominada História de Instituições Esco$\triangle$ lares analisa os múltiplos elementos constitutivos que auxiliam, ao longo - do tempo e em contextos diversos, na compreensão da gênese das escolas e na caracterização de sua atividade. Conforme explicam Nosella e Buffa (2009), estudar uma escola implica perscrutar as circunstâncias de surgimento e funcionamento, a organização do espaço, os materiais didático-pedagógicos, os sujeitos como alunos, professores e administradores, as questões curriculares, as políticas educacionais e as normativas. Essa metodologia compreende a escola como instituição complexa, sendo que uma pesquisa pode contemplar vários dos aspectos citados, ou apenas um deles.

Em algumas de nossas pesquisas, tratamos de instituições escolares criadas por imigrantes alemães e seus descendentes no sul do Brasil, que deram origem, nos séculos XIX e Xx, às denominadas escolas alemãs. Porém, de acordo com Santos (20I4: 240), devido à dinâmica histórica das relações socioculturais, essas instituições primordiais sofreram mudanças nas suas formas de organização:

Se, quanto aos primeiros anos de funcionamento das escolas daquela área de colonização, fica evidente a filiação com os referenciais culturais étnicos de base germânica, sobretudo centralizados nos usos do idioma alemão, dados do funcionamento das mesmas escolas, durante o decorrer das décadas de i9ıo e i920, denunciam transformações.

Considerando essa premissa, o objetivo deste estudo é analisar a origem da escola primária teuto-brasileira rural em Santa Catarina e sua instituição nas primeiras décadas do século xx. A metodologia é embasada na pesquisa documental, com o uso de relatório, estatutos, termos de visita de inspeção, estatísticas, livro, cadernos e fotografias. As análises são parametrizadas por bibliografia que aborda as relações entre a educação escolar e a imigração teuta para o Brasil meridional.

\section{Da origem identitária cultural: a imigração, a instituição da escola e a germanidade}

$\mathrm{Na}$ esfera das organizações societárias humanas, a ação de instituir envolve inicialmente uma origem, mas também posteriores permanências ou rupturas, 
A ESCOLA PRIMÁRIA TEUTO-BRASILEIRA RURAL: EDUCAÇÃO E SINCRETISMO EM SANTA CATARINA

ADEMIR VALDIR DOS SANTOS

que criam as condições históricas para a manutenção ou assunção de outra forma institucional. Admite uma dinâmica de acontecimentos capazes de gerar uma natureza específica e transformações que respondem às modificações dos contextos sociais, políticos, econômicos e de produção da cultura com os quais a instituição vai se relacionando ao longo do tempo, implicando que permaneça ativa ou, até mesmo, sua extinção. Nesse sentido, entendemos a viabilidade de caracterizar a emergência de uma nova forma histórica de escola em Santa Catarina. Para tanto, evocamos um fenômeno datado: o movimento de imigração alemã para o Brasil, responsável por colonizar porções do território nacional e que está vinculado às iniciativas de educação formal nesse ambiente.

A imigração alemã trouxe para as paisagens naturais e humanas brasileiras um conjunto de interferências culturais, principiando no século XIX e se estendendo até as primeiras décadas da centúria passada. Estudos como os de Rambo (2003), por exemplo, evidenciam relações entre a migração e a questão agrária, afirmando que, com ela, «o Sul muda de fisionomia», uma vez que a identidade dos colonizadores alemães imprimiu marcas no panorama socioeconômico do Paraná, de Santa Catarina e do Rio Grande do Sul, onde a estrutura fundiária passou a ser calcada na pequena propriedade da terra e o empreendimento laboral familiar, assentado na policultura, garantiu a subsistência inicial das famílias imigradas. Segundo estimativas:

Entre 1850 e 1909, entram no Brasil, em média, cerca de 15.000 alemães em cada década, no período anterior (I818-1849) foram registrados apenas 6.983 imigrantes encaminhados para as colônias de São Leopoldo (Rs), São Pedro de Alcântara e Mafra (sc) e Rio Negro (PR). O momento de maior afluxo ocorreu após a Primeira Guerra Mundial: na década de 1920, o Brasil recebeu pouco mais de 75.000 alemães, o que representa quase $30 \%$ do total. Os números se tornam inexpressivos a partir de 1938 [...] (Seyferth, 1994: 13).

Os imigrantes alemães foram responsáveis pela construção de uma identidade cultural: a germanidade. Contudo, esse não foi um episódio historicamente hegemônico, pois se inicialmente encontrou algumas condições propícias a sua formação, depois foi combatido. Pesquisas sobre a imigração alemã no território catarinense ratificam: «[...] a introdução, manutenção e difusão de elementos culturais e identitários de base germânica que ocorre desde o século xIX, em contextos ora harmoniosos, ora conflituosos, contribuiu para erigir um estatuto histórico de germanidade em Santa Catarina» (Santos, 20I5: 325).

Do mesmo modo, ao discutir as ligações entre imigração e cultura, Seyferth (1990) argumenta sobre a inserção e manutenção da identidade germânica no Brasil, que embora vinculada à cultura de origem, foi sujeita aos fenômenos de absorção, assimilação e aculturação; além disso, explica que o processo levou os imigrantes de mesma procedência a formar grupos étnicos mais ou menos organizados, identificados por valores culturais próprios. Nesse estudo antropológico, Seyferth (1990: 80) acrescenta que dentre os elementos culturais valorizados na imigração alemã: «[...] destacam-se a conservação do idioma e dos costumes, 
sendo que a diferenciação se afirma sobre valores religiosos, morais, familiares, associativos, culturais». Ou seja, os nutrientes da germanidade formaram uma base identitária, em relação à qual, por movimentos de integração e resistência, o repertório cultural brasileiro foi sendo absorvido, negado ou complementado. Além disso, com a inclusão de um tipo de escola próprio -a escola comunitária-, é possível elencar um conjunto de componentes societários que constituíram a etnicidade como marca dos imigrantes e de sua descendência:

O uso cotidiano da língua alemã, a organização escolar comunitária ou religiosa (com ensino em alemão), todo o complexo econômico e social originado da colonização baseada na pequena propriedade familiar policultora -para citar apenas algumas características- são anteriores à emergência da etnicidade, que reificou uma «cultura germânica» pretendida pelos imigrantes e seus descendentes, dando ao isolamento (geográfico/político) um caráter ideológico justificativo de limites étnicos. (Seyferth, 1994: I4).

Os imigrantes criaram suas pioneiras escolas, denominadas de alemãs. A escola alemã -deutsche Schule - era uma instituição peculiar, marcada pelo comunitarismo. Mas Santos (20I2: 560) acrescenta que o surgimento das escolas alemãs foi justificado pela carência de atendimento estatal, sendo alicerçado sobre uma plataforma cultural peculiar: «[...] pela ausência de instituições públicas, as escolas alemãs atenderam à finalidade social específica de fornecer instrução primária, embasadas por um conjunto de práticas educativas que mesclaram aspectos culturais estrangeiros àqueles do contexto brasileiro de então». Então, é possível argumentar que embora a germanidade fosse um motor propulsor, o ambiente cultural preponderante era o brasileiro, e, sendo assim, as escolas alemãs estiveram expostas a outras influências culturais.

Não obstante, realçamos um consenso entre os estudiosos da imigração, segundo o qual as escolas fundadas pelos alemães foram indispensáveis na organização da cultura, tornando-se um agente do germanismo. Destaca-se o papel da escola na geração e preservação étnico-cultural, marcando o movimento histórico de produção e reprodução de práticas humanas:

[...] a escola de fato representou um elemento de importância sem igual na colonização alemã do Rio Grande do Sul e de Santa Catarina. Sem ela, os imigrantes alemães dificilmente teriam conseguido neutralizar uma decadência cultural quase inevitável, instalados que foram em circunstâncias deveras hostis, tanto de natureza ambiental como sócio-cultural. Uma comunidade teuta sem escola carecia de um elemento essencial. A escola fazia parte integrante da comunidade e se constituía num equipamento fundamental no conjunto da vida e da atividade comunal.

A escola representou, assim, uma condição prévia e indispensável para a salvaguarda dos valores culturais e para a integração harmônica da vida da comunidade (Rambo, 1996, p. 95).

Portanto, entende-se a instalação da germanidade pela via da imigração e, ao mesmo tempo, dimensionando o trabalho da escola neste processo. Atentos às interações culturais entre a população nacional e os imigrantes, a seguir destacamos 
A ESCOLA PRIMÁRIA TEUTO-BRASILEIRA RURAL: EDUCAÇÃO E SINCRETISMO

EM SANTA CATARINA

ADEMIR VALDIR DOS SANTOS

o componente cultural teuto-brasileiro, trazendo dados sobre a sua conformação histórica.

\section{De alemão a teuto-brasileiro: a rota de um processo identitário}

Discutimos alguns aspectos da germanidade, intimamente relacionados à instituição da escola alemã. Mas como se originou o componente cultural teuto-brasileiro? Para responder, partimos do indicativo de que o termo é informado por uma tipologia nutrida em contatos interculturais. Compreendemos que denota a convivência entre sujeitos de matrizes culturais distintas - alemães e brasileiros. Quer dizer, a identidade teuto-brasileira foi formada na relação com uma herança de germanidade, na medida em que comunidades étnicas alemãs foram estabelecendo contatos com a sociedade brasileira. Para que surgisse um novo contexto, era essencial que ocorressem inter-relações entre componentes de natureza teuta e brasileiros.

Destarte, o que se formou foi resultante das possibilidades de combinação entre distintas vertentes culturais: o sincretismo. A identidade teuto-brasileira se nutriu de duas fontes: numa primeira, procurando manter os elementos da cultura original germânica; noutra, admitindo que aspectos da cultura brasileira fossem incorporados à identidade alemã. Surgiram as condições para a produção social de uma nova composição cultural onde a brasilidade foi sendo amalgamada à germanidade. Quanto à geração dessa identidade, Seyferth (1994) reafirma que esse novo traço identitário surgiu no convívio da comunidade alemã com a sociedade brasileira, mas incluiu, também, o compartilhamento do processo colonizador com imigrantes europeus de outras etnias:

A emergência da identidade étnica nada tem a ver com uma situação de isolamento/enquistamento; ao contrário, ela é decorrência do contato e do próprio processo histórico de colonização, que produziram tanto uma cultura camponesa compartilhada com outros grupos imigrados, como uma cultura especificamente teuto-brasileira (Seyferth, 1994: 13-4).

Diante do exposto, inferimos que a nomenclatura teuto-brasileira pode ser aplicada à caracterização tipológica de escolas que foram sendo instaladas como «núcleos de produção de relações sociais parametrizadas por questões étnicas, uma vez que se constituíram como uma experiência histórica engendrada nas relações entre a perspectiva cultural estrangeira e a brasileira» (Santos, 20I2: 540). Dito isso, a seguir tomamos como foco a escola primária teuto-brasileira rural, discutindo fatores de sua institucionalização.

\section{De escolas alemãs a teuto-brasileiras rurais}

As instituições escolares são constituídas de várias formas. Quanto às escolas de imigrantes alemães no Brasil meridional, por ocasião do Primeiro Colóquio de Estudos Teuto-Brasileiros, o pesquisador Egon Schaden propôs uma tipificação 
histórico-sociológica, considerando a sua origem, a localização geográfica e o grau de escolarização. De acordo com seus argumentos: «O sistema escolar teuto-brasileiro constitui-se de forma bastante complexa» e, em função disso, defendeu a denominação «escola teuto-brasileira rural» e, ainda, a distinção entre

$\mathrm{I}^{\circ}$, escolas alemãs propriamente ditas, surgidas, sobretudo em núcleos urbanos e mantidas, em sua maioria, por sociedades escolares; $2^{\circ}$, escolas comunitárias ou coloniais, características das zonas de fraca densidade demográfica, e, $3^{\circ}$, escolas mantidas por congregações religiosas alemãs [...]; [por fim, acrescentou que a] [...] segunda categoria correspondente à genuína escola teuto-brasileira (Schaden, 1966: 65).

Alegou que as áreas rurais manifestaram tendência à formação de um sistema cultural próprio, compreendido como sincrético na sua relação com o meio natural e com a população luso-brasileira, situando as escolas dos imigrantes alemães no contexto da colonização como «[...] instituição característica da cultura teuto-brasileira» (Schaden, 1966: 67). Por fim, sustentou que em decorrência de uma ambiência de elementos contraditórios e de ambiguidade de significados e funções, a escola rural teuto-brasileira emergiu no ambiente rurícola como instituição típica da cultura dos colonos, criada para suprir a ausência de escolas públicas. A presença dessa escola no meio rural a vincula à questão agrária, um dos motores da imigração europeia, que repercutiu na estrutura fundiária das colônias. Em suas análises, Seyferth (1990) entende a necessidade de considerar os vínculos entre o fenômeno imigratório e a pequena propriedade da terra, evidenciando a ruralidade.

O resultado mais significativo da colonização, contudo, está ligado à formação de uma sociedade rural diferente da sociedade rural brasileira tradicional, onde não havia lugar para o pequeno proprietário. De fato, o que ocorreu no Rio Grande do Sul, Santa Catarina, Paraná, parte de São Paulo, Espírito Santo e Mato Grosso do Sul, foi a formação e consolidação de uma sociedade camponesa, cuja base fundiária é a pequena propriedade policultora trabalhada pela família do proprietário; camponeses que mantêm um estilo de vida próprio, um modo de produção específico [...] (Seyferth, 1990: 2I).

A escola primária teuto-brasileira rural é, nesse sentido, resultante histórica de um empreendimento comunitário para a educação dos imigrantes e seus descendentes, engendrado num processo de colonização de terras marcado pelo campesinato. Ao corroborar uma interpretação conexa, Rambo (1996: 68) enfatiza que constituir uma comunidade era $\mathrm{o}$ «[...] elemento-chave da organização colonial teuto-brasileira», aplicando às escolas das zonas coloniais a denominação de "comunitárias». E ampliando a caracterização das escolas primárias teuto-brasileiras rurais, Fiori (1991: 68) traz outros fatores para tipificá-las, entendendo-as como «[...] escolas particulares, que se caracterizavam por transmitir valores culturais básicos das comunidades a que serviam e ministravam o ensino em língua não vernácula - geralmente alemão ou italiano».

Resulta, então, que as escolas primárias teuto-brasileiras rurais são definidas tanto por elementos dos contextos culturais como por meio de aspectos da 
internalidade das práticas educativas. Tendo em vista tais elementos, na próxima seção apresentamos nossas análises, guiados pelo objetivo de discutir a origem da escola primária teuto-brasileira rural em Santa Catarina e as condições de sua instituição.

\section{Instituição das escolas teuto-brasileiras rurais: sincretismo cultural em Santa Catarina}

Em Santa Catarina, a criação de escolas por imigrantes alemães e seus descendentes foi fecunda, influindo, no intervalo entre a década de 1820 e os anos 1940, na conformação de um cenário marcado por diversificação quanto às instituições escolares que o constituíram. Em meio a esse mosaico, individuamos a escola teuto-brasileira rural.

Para iniciar a discussão, trazemos os estatutos de uma escola estabelecida numa região de imigração alemã do nordeste catarinense, onde identificamos algumas normas quanto a sua organização institucionali. Os estatutos se referem à Sociedade Escolar Jaraguá gg e são assinados pelo presidente Hermann Schmidt, cujo nome encabeça a lista de sócios da associação. Foram manuscritos em um livro de capa dura, onde constam os termos de abertura e de encerramento, ambos redigidos em português, datados de 29 de dezembro de i9I5. Mas o teor dos estatutos, composto por seis artigos manuscritos em tinta preta e distribuídos entre as páginas três e dez, tem sua redação em alemão, sob o título Statuten der Schulverein Jaraguá no. 99. A Schulverein, ou seja, a Sociedade Escolar era uma associação comunitária vinculada à igreja evangélica luterana, o que assinala o artigo um, que trata dos seus objetivos e do local de atuação:

A sociedade escolar evangélica Jaraguá 99 tem como objetivo dar às crianças de sua associação uma boa educação escolar. Para este propósito, a sociedade receberá seu próprio terreno com edifício; comprado para essa finalidade e fica na rua principal Jaraguá «sob número 99» (Jaraguá do Sul, igrs: 3, tradução nossa)2.

O patrimônio da Sociedade Escolar é definido no segundo artigo: «Um terreno, localizado na rua Jaraguá, Frente: Estrada Jaraguá, [...] Área: 25.000 metros quadrados. Uma casa enxaimel, pintada, sem reboco e de tijolos. Um galpão aberto» (Jaraguá do Sul, 1915: 3, tradução nossa)³.

Os estatutos compõem um fundo do Arquivo Histórico Eugênio Victor Schmöckel, localizado em Jaraguá do Sul. O conjunto documental é referente ao período entre igis e 2007, sendo uma parte em alemão. Essa centenária instituição é hoje denominada Escola Municipal de Ensino Fundamental Antônio Estanislau Ayroso.

No original: «Der evangelische Schulverein Jaraguá 99 bezweckt den Kindern ihres Verein einen guten Schuluntericht zu geben. Hierzu besitzt der Verein ein eigenes Grundstück mit Gebäude; endgültig hierfür angekauft und liegt dasselbe an der Hauptstrasse Jaraguá "sob no. 99"».

No original: «Ein stück Land, gelegen and der Strasse Jaraguá, Front: Strasse Jaraguá, [...] Flächeninhalt: 25.00o quadratmeter. Ein Haus mit Fachwerk, gedielt, ausgemauert und mit Ziegeln gedekt. Ein offener Schuppen». 
A parte inicial desses Estatutos valida uma forma histórica de surgimento das escolas de imigrantes, pautada pelo senso de comunidade e pela filiação religiosa. Sobre seu caráter associativista, finalidade social e vínculo com a igreja, Seyferth (1990:53) ratifica:

A organização escolar teve especial importância no caso dos imigrantes alemães. Mesmo quando ligadas às igrejas -católica ou luterana-, as escolas teuto-brasileiras se organizavam em sociedades escolares (as Schulvereine), possuíam currículos comuns, assim como livros escolares comuns [...]. O maior número era de escolas primárias, alfabetizando em alemão.

Trazemos outros dados, desta vez sobre a origem de uma escola primária da região rural denominada Jaraguá I número 84, então pertencente ao município de Joinville, no norte catarinense. A movimentação para a sua criação consta nas fontes que registram a atividade da Jaraguá Gemeinde no. 84, fundada em I899. O termo germânico Gemeinde, que significa comunidade, é usado na identificação de um dos documentos examinados, o Conto-Buch no. I. Também escrito em alemão, é uma espécie de livro contábil que registra a movimentação financeira da associação comunitária do período entre I899 e 1913. A cada página consta o nome de um membro ou sócio (Mitglieder) da Comunidade Católica Escolar de Jaraguá 84, assim como o número do lote de terra (Kolonie) de que era proprietário e o valor da sua contribuição mensal. Já outro livro, identificado pelo número II, sistematiza o balanço financeiro referente ao período entre 1908 e r923. As duas fontes comprovam o mecanismo de sustentação financeira para a criação e funcionamento de uma escola cuja finalidade era atender os filhos dos membros da comunidade, que ao aderirem às regras estatutárias, tornavam-se sócios contribuintes.

Se os livros contábeis da Jaraguá Gemeinde no. 84 estão escritos em alemão, os seus estatutos, denominados Estatutos da Sociedade Escolar Catholica de Jaraguá I (número 84) e datados de 14 de janeiro de 1907 , foram registrados em língua portuguesa. A redação contém catorze títulos, que se desdobram em trinta parágrafos, preservando detalhes sobre a operação das associações escolares fundadas por imigrantes. Naquilo que é possível ler, apesar do sofrível estado de conservação do documento, a redação desvela diversos aspectos ${ }^{4}$. Ali constam detalhamentos sobre a sede, os direitos dos sócios, o modo de administração pela diretoria eleita, o formato das assembleias e as propriedades da comunidade, além de outras normativas como as que estabelecem as condições para uma eventual dissolução da sociedade escolar. Por meio dessa análise sublinhamos não somente detalhes quanto ao processo de instituição escolar, mas também o aspecto linguístico que é caracterizado pelo bilinguismo.

E haja vista a riqueza de elementos que os estatutos trazem quanto à criação de uma escola através desse formato associativo-comunitário, passamos ao exame

4 Segundo a direção do Arquivo Histórico Eugênio Victor Schmöckel, a documentação recebida estava danificada por rasgados na primeira página. A escola a que se refere está ativa, sendo denominada Escola Municipal de Ensino Fundamental Luiz Gonzaga Ayroso. 
de alguns dos seus artigos. Os itens iniciais desses Estatutos revelam dados quanto à natureza da associação, tais como a sua composição, a vinculação com a igreja católica e o ensino em dois idiomas distintos, o português e o alemão:

I. Da séde da Sociedade

$\int$ I Os abaixo assignados reunem-se sob a denominação «Sociedade Escolar Catholica no Jaraguá i (no. 84) a uma sociedade com a sede no Jaraguá I.

II. Da sociedade e seus fins

A Sociedade Escolar Catholica [tem] por fim proporcionar aos filhos de seus sócios uma instrucção primaria por meio das línguas vernácula e allemã [...]

III. Dos Socios

Serão admitidos como sócios [...] as pessoas de confissão catholica e que se obrigarem por sua assignatura a sujeitar-se a estes estatutos (Joinville, 1907).

Remetemos ainda a outros pontos da escrita, respondendo a questionamentos sobre como as sociedades escolares sobreviveram naqueles contextos e mantiveram a atividade de escolas próprias. Conforme se vê, a Sociedade Escolar era zelosamente gerida por sua diretoria, cuja composição que é detalhada no título referente à administração:

III Da administração

\I4 A sociedade regulará a sua administração:

I) Pela assemblea geral;

2) Pela directoria.

Á assemblea geral caberá a ultima e final decisão em todos os assuntos concernentes á sociedade.

Tendo empate na votação decidirá a directoria (Joinville, 1907).

Logo, as sociedades escolares constituíam uma diretoria, mas sem desprezar o valor democrático das assembléias. Os Estatutos trazem, ainda, o que competia à direção, que estendia sua supervisão e controle não apenas às questões financeiras, mas se ocupava de aspectos de cunho pedagógico tais como a aquisição de livros e a contratualização entre a comunidade e o professor:

$\mathrm{X}$ Das attribuições da directoria

\16 Á directoria em commum compete:

I) Fiscalizar o ensino,

2) Cuidar do pontual pagamento do ordenado do professor,

3) Apresentar balanço na assemblea geral annual, sobre o anno administrativo findo;

4) Inventariar solicitamente a propriedade da sociedade, registrando todas as alterações que se derem;

\17 Dos membros da directoria compete ao:

Presidente e em seus impedimentos ao substituto:

I) Presidir e dirigir as assembleas geraes;

2) Promover asssembleas estraordinarias (sic) não só quando fôrem necessárias para a boa marcha da administração, mas tambem quando requeridas por um terço dos socios quites de suas obrigações para com a sociedade. 
3) marcar as reuniões da directoria, que fôrem necessárias ou requeridas por tres membros da directoria;

4) representar a sociedade em Juizo;

5) encommendar ou comprar livros e outros utensilios referentes aos fins do ensino, assim como engajar, por contracto, o professor da sociedade (Joinville, 1907).

E foi possível ratificar dados quanto ao pagamento de mensalidades e à solicitação de uma «joia de entrada», que, em alguns casos, era exigida de quem pretendia se associar. Mas julgamos vital sublinhar que ambos os fatores estão relacionados à obrigação de enviar os filhos à escola:

[...] Direitos dos sócios

2) pagar uma jóia de entrada [...] mensalidades fixadas pela assemblea geral;

3) cumprir todas as obrigações, legalmente contrahidas com a sociedade e responder solidariamente com os seus haveres quando e em quanto não chegar a fortuna social;

4) mandar a seus filhos da idade de 8 até 12 annos para a escola dos dias uteis, e os da idade de I2 até I4 annos para a escola do domingo'.

\13 Deixando um socio por motivos futeis de mandar a seus fihos para a escola, terá a directoria o direito de intervir (Joinville, I907).

Ou seja, tanto nos Estatutos da Jaraguá Gemeinde, como no trecho dos Estatutos da Sociedade Escolar Jaraguá número 99 que preconizavam «dar às crianças de sua associação uma boa educação escolar», fica evidente o valor que os imigrantes alemães davam à escola. Reafirmando tal perspectiva, voltamos ao conteúdo do artigo in dos Estatutos da Sociedade Escolar Evangélica Jaraguá número 99 (Evangelische Schulverein Jaraguá no. 99), em que foi especificada a faixa etária das crianças a quem se destinava a escola: Jedes ihrer Kindern von 8 bis 13 Lebensjahre zur Schule zu schicken, ou seja «Para enviar cada um dos seus filhos dos 8 aos I3 anos de idade para a escola» (Jaraguá do Sul, I9I5: 4, tradução nossa).

Nesse âmbito, o que também vem à tona é a influência do fator religioso nas iniciativas de criação de escolas, uma vez que era inadmissível que as crianças ficassem alijadas, seja da educação escolar como do ensino religioso. No caso da escola de Jaraguá número 84, preconizava-se uma formação vinculada ao catolicismo. Já na comunidade de Jaraguá número 99, seriam atendidos os fundamentos do protestantismo luterano.

Sobre o catolicismo e sua vinculação com a escolarização, Rambo (i996: I4) destaca os Estatutos da Associação de Professores e Educadores Católicos do Rio Grande do Sul, datados de 1902 e também elaborados no contexto da imigração alemã, de onde extraímos a finalidade daquela entidade, trazida no parágrafo 2. ${ }^{\circ}$ :

A escola dominical realizava o ensino da catequese, vinculado à vida religiosa. Entre os católicos, compreende os estudos de Primeira Comunhão e Crisma. 
[...] propõe como finalidade geral a educação da juventude cristã, calcada nos princípios da Igreja Católica. Em particular propõe-se: fomentar a educação escolar; a preservação e o aperfeiçoamento das nossas escolas católicas paroquiais; a formação de um professorado eficiente e fiel aos seus deveres; a promoção dos interesses espirituais e materiais dos professores e a aquisição de material de ensino adequado.

Quanto às influências do ideário luterano, os estudos de Santos e Cecchetti (2018: 302) revelam que a imigração alemã foi o principal veículo de inserção do luteranismo, ratificando que as relações «[...] entre o pensamento de Lutero sobre a educação, a imigração alemã que trouxe para o sul do Brasil o luteranismo, e o processo de criação e manutenção de escolas nas comunidades de religião luterana constituem um amálgama histórico catalisado pela fé».

Soma-se às relações entre educação e religião o fato de que, em alguns casos, além de ser um espaço para o atendimento educacional formal, a edificação destinada à escola podia também ser ocupada para os serviços religiosos. Ou vice-versa. Isto porque nos relatos sobre a criação de uma escola na colônia Hammonia, situada na região do Alto Vale do Itajaí, Wiese (20II: 163) registra: «Em meados do ano de 1903, os membros da Comunidade Evangélica de Hammonia, sob a liderança do Pastor Aldinger, decidiram construir uma igreja que servisse também de escola». Por sua vez, Rambo (1994: 18) ressalta a importância atribuída à educação escolar pelos imigrantes, que precedia a atenção para com um local destinado aos ritos religiosos, pois havia uma

[...] preocupação que animava os emigrantes em relação à escola e à educação. Ao mesmo tempo em que ocupavam novas fronteiras de colonização, garantiam antes de mais nada a instalação de uma escola. Antes mesmo de pensar em construir uma igreja tratavam de edificar uma escola, a qual, não poucas vezes, servia de local provisório para o culto. Derivou-se daí um conceito intimamente ligado à vida das comunidades: a escola capela (Schulkapelle).

A existência de escolas capela expõe formas de organização espacial das escolas de imigrantes que conectam a compreensão de outros elementos da sua tipificação como teuto-brasileiras. Lembramos que a questão espacial diz respeito à geografia das regiões onde as escolas se instalaram, à arquitetura das edificações, mas também ao mobiliário como carteiras, armários e quadro-negro e, ainda, a utensílios didáticos como livros e cadernos, entre outros. Como Hernández Díaz (2002: 225, tradução nossa), que reconhece o papel da cultura material escolar como mediadora sociocultural: «Os objetos, ferramentas e materiais da sala de aula foram e são um instrumento de comunicação, ontem e hoje. São elementos de intermediação social e cultural. As coisas, objetos físicos e materiais da escola nos falam tanto, ou mais, do que as palavras ou gestos do professor ou das crianças» ${ }^{6}$.

6 No original: «Los objetos, los útiles y materiales del aula fueron y son instrumento de comunicación, ayer y hoy. Son elementos de intermediación social y cultural. Las cosas y objetos físicos y materiales de la escuela nos hablan tanto, o más, que las propias palabras o gestos del maestro o de los niños». 
Diante disso, indagamos por materiais e elementos de infraestrutura que estão na origem das escolas teuto-brasileiras rurais e, posteriormente, suportaram sua atividade. Nessa busca, localizamos livros e cadernos escolares utilizados por alunos e professores das escolas teuto-brasileiras, preservados em arquivos públicos e privados. Dentre eles, destacamos um manual denominado Minha língua: grammatica portuguesa para uso nas escolas allemãs no Brasil - Portugiesisches Sprachbuch für die deutschen Schulen in Brasilien, que desde o título, em português e alemão, revela o sincretismo linguístico que permeou o ambiente escolar. Salientamos ainda dois cadernos de tradução, um de 1930 e outro de 1946 . O primeiro apresenta listas de vocabulário que colocam, lado a lado, termos na língua vernácula e seu correspondente em alemão. O segundo contém traduções de pequenos textos e listas de «palavras difíceis». Diante desses objetos da cultura material escolar, concordamos com Santos (2009, p. 518): «A existência desse tipo de material ratifica a necessidade que havia de ensinar a língua portuguesa aos alunos da época, imprimindo o bilinguismo nas rotinas das escolas teuto-brasileiras (alemãs)». As relações entre a escola e a questão da aculturação linguística estabeleciam um problema central, que, de acordo com Schaden (1966: 70), ignorou os limites para a assimilação, pelos alemães e seus descendentes, do idioma utilizado pelo grupo étnico brasileiro (ou luso-brasileiro), assim como superestimou o potencial do ensino da língua do grupo dominante nas escolas primárias situadas nas zonas de colonização estrangeira:

Correspondendo antes ao objetivo prático de vincular os imigrantes à esfera mais ampla da comunidade étnica dominante no país, esses planos nada tinham que ver com a feição mística assumida mais tarde pela concepção da unidade cultural. Ninguém pensava ainda em exigir dos colonos, nem de seus filhos, que deixassem de falar o alemão como língua materna; haveriam de aprender o português para se entenderem com o resto da população.

Retomando a questão das edificações destinadas a abrigar escolas, remetemos às pesquisas de Santos (20I2) sobre um empreendimento de imigração alemã fundado em I897, administrado pela Companhia Colonizadora Hanseática e que ocupava 650 mil hectares do norte e nordeste de Santa Catarina - a Colônia Hansa -, as quais mostram que os prédios escolares foram sendo construídos aos poucos, conjugando esforços das comunidades e da empresa colonizadora. A investigação relata ainda que, apesar dessas empreitadas, existiu até mesmo o uso de uma choupana enquanto a escola não fosse concluída, assim como foram oferecidas aulas em casas de particulares, o que configurava uma espécie de escola doméstica (Hausschule).

Igualmente, localizamos referências à existência de uma escola capela na documentação da Sociedade Escolar Catholica de Jaraguá I (no. 84). Seus estatutos revelam que num dos dois terrenos da sociedade havia uma edificação arquitetonicamente caracterizada como igreja, mas que também era usada para as práticas escolares. Além disso, foi estipulado que o outro lote poderia ser utilizado pelo professor, mediante a exploração do solo para a agricultura ou a criação de animais. Nos termos do documento: 
XII Da propriedade da sociedade.

$\int 22$ A propriedade da sociedade consiste em dois terrenos da superfície total de $4^{1 / 4}$ hectares. Um dos terrenos, sito á margem esquerda do Rio Jaraguá, entre os lotes coloniaes no. 84 e 86 , achando-se n'elle a igreja, que serve também para o ensino escolar, fica esclusivamente destinado para fins escolares, enquanto o outro, sito no Valle do Ribeirão dos Hungaros, poderá ser aproveitado pelo professor, entretanto, sómente quando houver feito contracto formal com a directoria (Joinville, 1907).

A íntima associação entre educação e religião, ou se quisermos, entre escola e igreja, é um dado cultural instituidor, corroborando para a formação das escolas teuto-brasileiras rurais. Apresentamos, na Figura I, uma icônica representação a respeito, capturada numa fotografia da escola de imigrantes alemães e húngaros da Comunidade Santa Cruz, situada em Jaraguá do Sul. Datada de 1937, a cena congrega algumas famílias de membros da Gemeinde Heilig Kreuz. Em posição de destaque, de pé entre o grupo de homens e segurando uma bíblia, identificamos o professor e capelão Wendelin Schmidt. À frente temos meninos e meninas, estudantes daquela escola rural. A cena foi montada diante da construção em estilo enxaimel, em cuja cumeeira frontal há uma cruz, o que confirma os registros de que o prédio era simultaneamente utilizado como escola primária e para as cerimônias do catolicismo.

Figura i. Comunidade Santa Cruz. Edifício da escola capela, I937

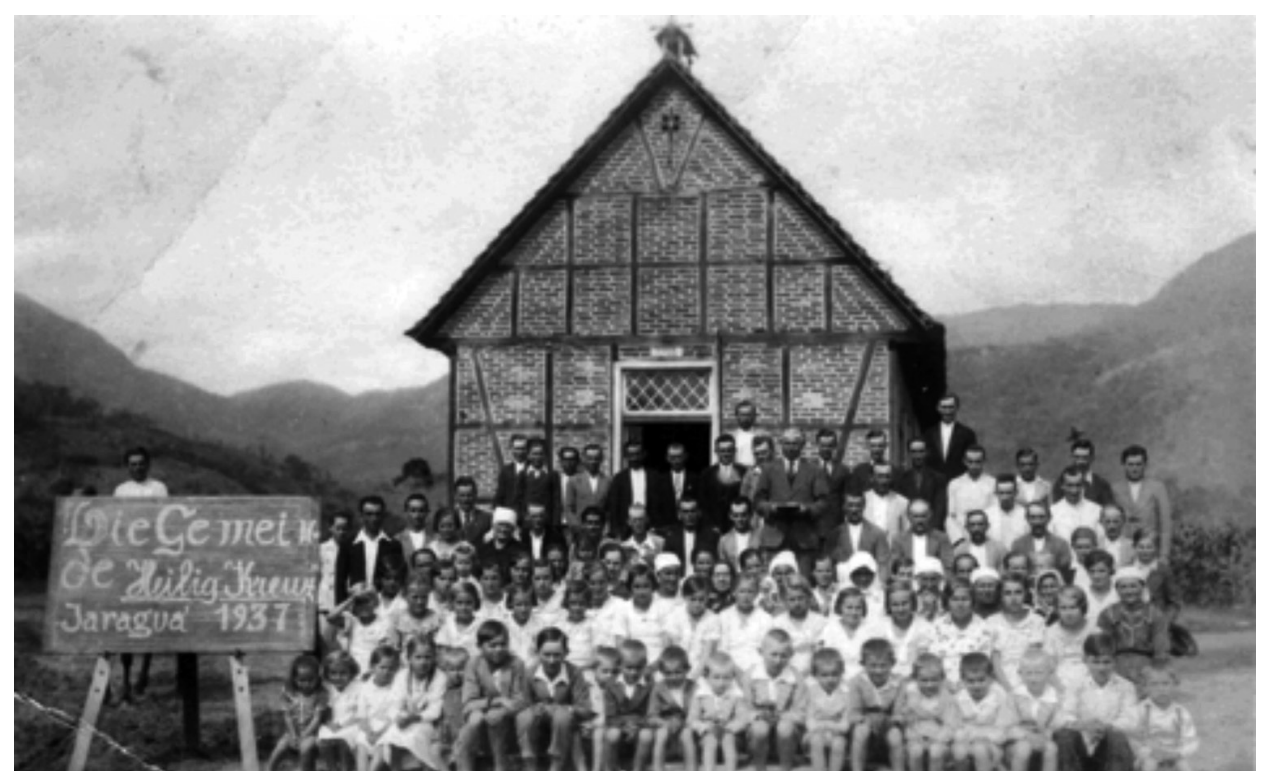

Fonte: Arquivo Histórico Eugênio Victor Schmöckel.

A tipificação das escolas primárias teuto-brasileiras rurais foi reforçada pelas consultas a documentos de administração e controle de escolas catarinenses das 
décadas de 1930 e 1940, os quais revelam que mesmo tendo sido modificado o estatuto jurídico, diversas instituições mantiveram aspectos ligados ao seu surgimento nos contextos da imigração alemã. Um formulário estatístico datado de I944 e relativo à Escola Municipal Rui Barbosa, por exemplo, nos traz alguns dos fatores que ratificam a sua origem no associativismo das comunidades alemãs, como a dedicação à agricultura enquanto atividade econômica principal e o uso do prédio da igreja pela escola.

Ensino Primário geral - 1944 Informação anual à-cêrca da organização e aproveitamento

Escola Municipal Rui Barbosa, Pedra de Amolar, Corupá, Jaraguá do Sul

Distância da sede distrital $9 \mathrm{~km}$, de sede municipal Jaraguá do Sul $52 \mathrm{~km}$,

Casas da localidade 66; população 422

Principais atividades da população: culturas agrículas (sic), extração de madeiras; Ascendência da população: alemã

PRÉDIO: Pertence a Sociedade Evangélica Ano de construção: 1933

Com que fim foi construído? Para fins de Igreja (Jaraguá do Sul, 1944a).

O mesmo documento revela que o atendimento escolar era feito das 8 às I2 horas, para uma classe única composta por alunos do I. ${ }^{\circ}, 2^{\circ}$ e $3 .^{\circ}$ anos. Quanto à arquitetura, o prédio ocupava uma área edificada de $96 \mathrm{~m}^{2}$, num único pavimento com paredes de tijolos, assoalhado e coberto com telhas de barro. Havia um mictório e dois banheiros, embora a escola não dispusesse de água encanada, de fossa e de luz elétrica. Constam ainda informações sobre o Ensino Religioso, que era ministrado em uma aula semanal, vinculado à religião Evangélica (luterana) e com frequência de 90\%, que correspondia a 22 alunos (Jaraguá do Sul, 1944a).

De modo a compreendermos as dinâmicas históricas, acompanhamos questões de funcionamento e de uso da infraestrutura dessa mesma escola, expressos em termos de visita de inspeção. Num deles, dos dias 25 e 26 de maio de 1948, consta: II. $^{\circ}$ - que a matrícula total era de 59 alunos, sendo $4 \mathrm{I}$ do I. ${ }^{\circ}$ ano, 8 do $2 .{ }^{\circ}$ ano e ro do $3 .^{\circ}$ ano; [... $3^{\circ}$. - que a sala de aula é o Templo evangélico que vem servindo para sala para aula» (Jaraguá do Sul, 1948a). Já em 2I de agosto de I948, o inspetor Emílio da Silva registrou: « $3 .{ }^{\circ}$ - que a sala de aula estava bem asseiada e conservada - servindo a mesma para atos religiosos - Evangelico Luterano» (Jaraguá do Sul, 1948b, sic). E no termo de visita do ano seguinte temos: «I. ${ }^{\circ}-$ que a matrícula total era de 48 alunos, sendo 36 do r. ${ }^{\circ}$ ano, 2 do $2 .^{\circ}$ ano e 4 do $3 .^{\circ}$ ano; $2 .^{\circ}-$ que faltaram 6 alunos, sendo 6 do r. ${ }^{\circ}$ Ano; $3 .^{\circ}-$ que a sala de aula é o recinto do tempo evangellico lutherano em bom estado de conservação e limpo» (Jaraguá do Sul, 1949). Vê-se que, em certa medida, a situação dos primórdios se perpetuava, naturalizando o uso das dependências da pequena igreja como sala de aula da escola multisseriada local. Logo após, no termo de inspeção de 29 de novembro de 1950, foram acrescentados detalhes sobre o mobiliário utilizado: «3-que a sala de aula é o recinto principal do templo evangélico e que estava regularmente conservada e limpa; 4 - que havia 2 quadros negros, um armário, I mesa, 3 cadeiras, 
A ESCOLA PRIMÁRIA TEUTO-BRASILEIRA RURAL: EDUCAÇÃO E SINCRETISMO EM SANTA CATARINA

ADEMIR VALDIR DOS SANTOS

2I bancos com 3 lugares cada, tudo em estado regular de conservação para suprir as necessidades do momento» (Jaraguá do Sul, 1950).

Nossas análises não salientam apenas o modo de organização e funcionamento daquelas escolas, mas reforçam que esses aspectos eram comuns entre o conjunto de instituições catarinenses, chegando ao ponto em que os instrumentos estatísticos de coleta incorporaram como opções de resposta aqueles dados peculiares das escolas catarinenses das zonas de imigração. Note-se o que foi informado quanto a uma unidade classificada como escola isolada no documento Ensino Primário geral - 1945 Informação anual à-cêrca da organização e aproveitamento, assinado pelo inspetor Manoel Luiz Silva em ro de janeiro de 1946. O instrumento mescla informações que desvelam o sincretismo que conformou a identidade cultural teuto-brasileira: a vinculação a duas entidades mantenedoras diferentes, a presença de imigrantes de diversas origens convivendo com a população brasileira (indicada pela ascendência de portugueses) e a filiação ao protestantismo, que devia conviver com as tradicionais raízes católicas brasileiras.

Escola Isolada Municipal Lauro Müller

a) Entidade mantenedora: Natureza: Governo Municipal

b) Espécie: Comunidade Evangelica

2. População, local, ascendência e atividades:

Donde procederam os primeiros povoadores do luar? De que país e provincia on cidade, ilha etc? Alemães

Os atuais habitantes, em sua maioria, são descendentes de: alemães, portugueses, italianos, russos

Qual o numero de habitantes do lugar? 250

Qual o numero de prédios: 78

Características do prédio

Nome do proprietário: Comunidade Evangélica [no mesmo campo está escrito Propriedade Municipal, o que está riscado]

[...] Em que ano foi construido o prédio: em 1928

Com que fim foi construido? Para escola e capela (Clube, hotel, capela etc.) (Santa Catarina, 1946, grifos nossos).

Com o intuito de acrescentar às nossas análises e aos argumentos decorrentes, buscamos dados quanto à origem da Escola Isolada Municipal Lauro Müller, movidos pelos seguintes questionamentos: quais as circunstâncias de criação da escola e as características do prédio erigido em 1928 ? Esse momento da pesquisa foi frutífero, sendo alimentado a partir do momento em que localizamos fotografias referentes a uma escola filiada à Sociedade Escolar Paulstrasse, ou Estrada Paulo, da localidade mais conhecida como Rio Paulo, que estava situada no distrito Hansa Humboldt, em área rural então pertencente ao município de Joinville. Primeiramente, a Figura 2 mostra a festa de colocação da pedra fundamental do prédio escolar. Destacamos na imagem a existência da edificação que servia como escola e residência do professor. As marcas do ambiente rural são evidenciadas pela vegetação do entorno, assim como pela pastagem ao fundo, onde se alimentava o gado. Percebe-se o apuro no vestir das pessoas, indicando a relevância do 
evento para a população retratada, composta por homens, mulheres e crianças de várias idades.

Figura 2. Festa de colocação da pedra fundamental da Escola de Rio Paulo, 1928

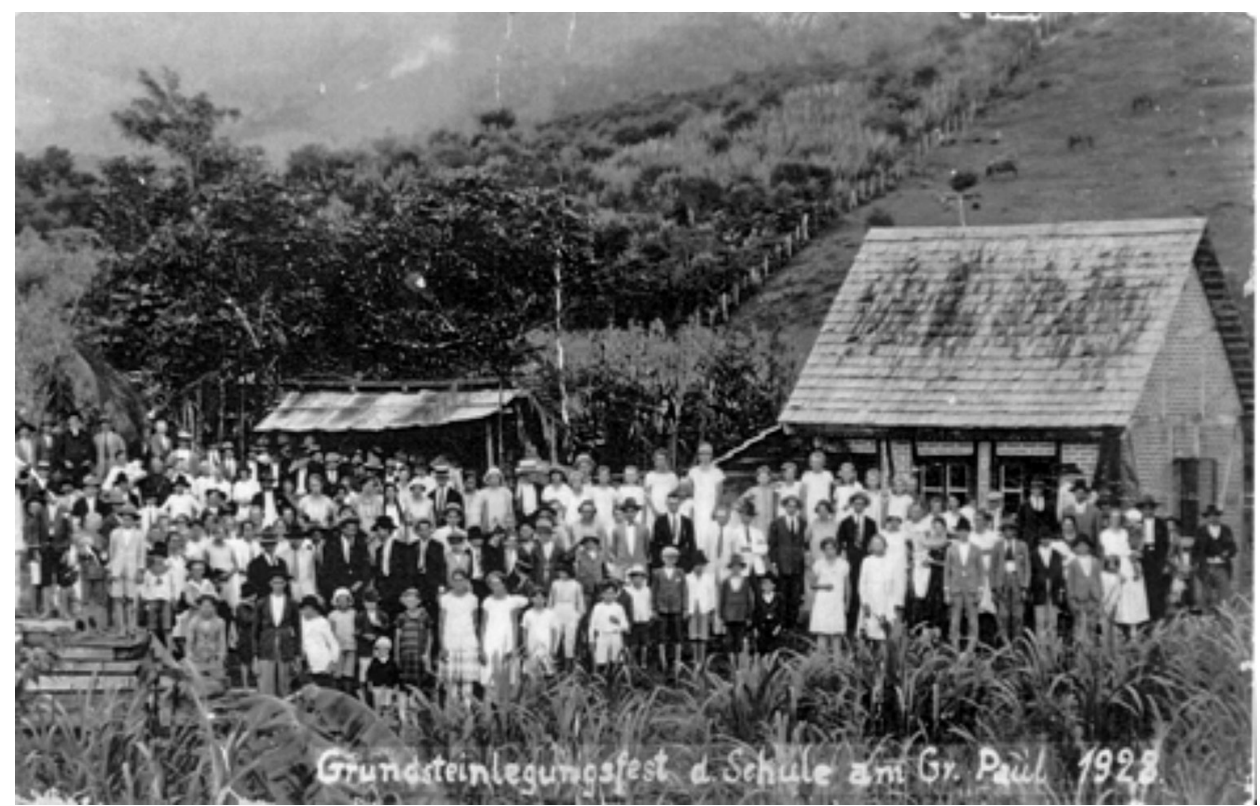

Fonte: Arquivo privado.

O lançamento da pedra fundamental foi motivo de festa, identificado em alemão: Grundsteinlegungsfest. Mas imaginemos o contentamento com a inauguração da nova escola, acontecido no mesmo ano e representado na Figura 3. Além disso, há que se pensar nas dificuldades para construir um edifício naquela distante região rural e com poucos recursos.

Voltamos a nossa atenção para as inscrições colocadas na fachada do prédio à esquerda, correspondentes à data da fundação e ao nome da escola, sendo este grafado em português: Escola Rio Paulo. Paradoxalmente, a identificação anotada sobre a foto está em alemão: Eiweibung der Schule am Rio Paulo I928 (inauguração da escola no Rio Paulo I928). A convivência entre dois idiomas simboliza a permanência do sincretismo cultural.

Mediante o objetivo de conhecer a instituição de Rio Paulo, extraímos alguns dados de estatísticas educacionais do Estado de Santa Catarina, referentes à escola da Sociedade Escolar Paulstrasse. Então descobrimos que ela tinha assumido uma nova denominação. Ou seja, tratava-se da Escola Isolada Municipal Lauro Müller, que: recebia uma subvenção de Cr\$ 2 400,00 [Cruzeiros]; estava situada numa localidade que tinha aproximadamente 67 casas e uma população de 470 pessoas de ascendência alemã, italiana ou polonesa, cujas principais atividades econômicas 
Figura 3. Inauguração da Escola de Rio Paulo em 1928

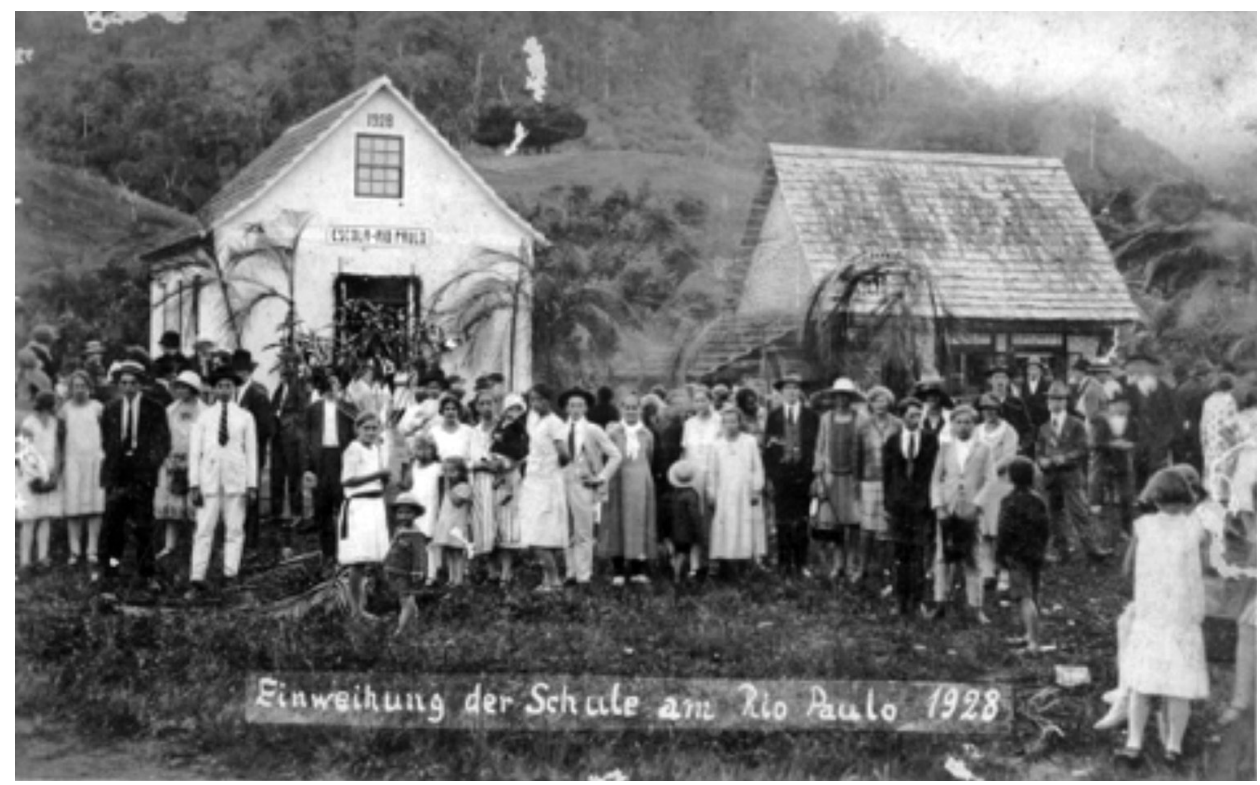

Fonte: Arquivo privado.

eram «agricultura e criação, engenho de serra e de cana»; «A casa fica à disposição do governo»; o "Ano de Construção: 1928» e "Com que fim foi construído: Escola» (Santa Catarina, I944). Consta ainda uma área edificada de $54 \mathrm{~m}^{2}$ e que a escola não possuía luz elétrica nem cozinha, embora contasse com dois banheiros, apesar de não haver água encanada e fossa. Da parte do documento identificada como Diversos, retiramos elementos complementares: "Na localidade há rádios -receptores? Quantos? 2 Nas horas de folga, em que se ocupa o Professor? Em trabalhos agrícolas À localidade chegam jornais frequentemente, e de onde? De Joinvile Quais as religiões: (mista) Evangélica e católica» (Santa Catarina, 1944). Ou seja, as fontes confirmaram questões históricas anteriormente identificadas, evidenciando que na década de 1940 as instituições oriundas das escolas de imigrantes se mantinham sob a égide do sincretismo cultural forjado ao longo das primeiras décadas do século xx, podendo ainda ser entendidas como escolas primárias teuto-brasileiras rurais. Do que a Escola Isolada Municipal Lauro Müller, antiga Paulstrasse Schule, é exemplo vivo!

Numa fonte oriunda da inspeção escolar municipal, subscrita pelo professor Manoel Luiz Silva, denominada Informações referentes a sociedade escolar (antiga escola alemã), de 25 de maio de 1944 e concernente à Escola Isolada Municipal Osvaldo Cruz de Estrada Isabel Alto, distrito de Corupá, município de Jaraguá do Sul, encontramos outros dados ratificando o processo de conformação institucional próprio das escolas teuto-brasileiras. Consta que aquela escola teve origem na iniciativa da Sociedade Escolar Isabel Alto II, fundada em I92I, cujo 
patrimônio e vinculações legais sublinham a ligação com a Sociedade Colonizadora Hanseática de Hamburgo, além de trazer a composição da diretoria:

\section{Patrimônio}

Lote no. I68 «A» O,4I hectare, ou seja 4.I0o m², uma casa de tijolos, I2 bancos, 2 quadros-negros, uma mesa. A sociedade possui estatutos registrados e escritura, ou titulo definitivo expedido pela Sociedade Colonisadora Hanseatica. [...] O prédio está em boas condições, merecendo apenas reparos; o terreno é cercado.

A Diretoria compõe-se de três membros. Presidente: Emilio Bleich Tesoureiro: Henrique Schultz Secretario: Walter Anders (Jaraguá do Sul, 1944b).

Existem também documentos falando da criação de associações intraescolares, cujo intento era introduzir nas escolas de imigração um currículo que levasse ao abrasileiramento da população infantil e, de modo indireto, que atingisse suas famílias ${ }^{7}$. Dentre elas, destacamos as Ligas Pró-Língua Nacional, que pretendiam combater o uso do idioma estrangeiro, atacando os erros na escrita e a má pronúncia do português entre as crianças de ascendência alemã. Este ente escolar recomendava, ainda, a apresentação de vultos da história brasileira, que deveriam ser conhecidos e venerados como modelos. Vejamos como esses aspectos aparecem no instrumento de informação estatística da Escola Municipal Rui Barbosa:

24 - Liga Pró-Língua Nacional: fundação 9 de abril de 1942

Quais os trabalbos efetuados durante o ano? Álbuns e centros de interesse Cartas enviadas durante o ano. Quantas? 2 A quem? Aos alunos da Escola Pedra de Amolar Alto

A Liga instalou patronos, nas salas de aula? Sim Quantos e quais? I Rui Barbosa Os alunos das primeiras séries têm sotaque estrangeiro? Sim Todos ou parte? Sim

Qual o idioma que essa prosódia reflete? Alemão (Santa Catarina, 1944a, grifos nossos).

As pesquisas de Luna (2000), que examinaram fenômenos relativos à língua nas comunidades de imigrantes de Santa Catarina, afirmam que o Programa Liga Pró-Língua Nacional foi uma iniciativa da Inspetoria Geral das Escolas Particulares e Nacionalização do Ensino e estava vinculado à proibição dos direitos linguísticos da população teuto-brasileira, estabelecido pelo Decreto-Lei no. 88, de 3I de março de I938. Sobre a ação das Ligas acrescenta:

Embora tenham sido propostas para todas as escolas públicas do Estado, as atividades das Ligas estiveram mais relacionadas àquelas escolas de regiões de imigração. As Ligas foram criadas com o objetivo expresso de fomentar nos alunos o interesse pela defesa e difusão dos valores nacionais. Nesse sentido, as atividades propostas pela Inspetoria envolviam a valorização e, em alguns casos, a exaltação de

Conforme SANTOS (20I0), o auge do abrasileiramento nas zonas de imigração alemã catarinenses está no período ditatorial do Estado Novo (1937-1945), quando medidas nacionalistas buscaram reconfigurar a organização escolar historicamente construída por meio da formulação de políticas e práticas educativas. 
A ESCOLA PRIMÁRIA TEUTO-BRASILEIRA RURAL: EDUCAÇÃO E SINCRETISMO

EM SANTA CATARINA

ADEMIR VALDIR DOS SANTOS

todos os traços da cultura e do Estado brasileiro, entre outros, a língua portuguesa. (Luna, 2000: 56).

Tais análises confirmam a imposição de um padrão de funcionamento escolar nitidamente nacionalista a partir do final da década de 1930, estimando que seus influxos determinassem transformações institucionais nas pioneiras escolas de imigrantes alemães. Foi sendo engendrado um amálgama de elementos culturais teutos com outros tipicamente brasileiros, esses reconhecidos como válidos. Eis o conflituoso caminho de construção do modelo escolar teuto-brasileiro, aplicável às escolas primárias de áreas onde a imigração alemã fincou raízes.

\section{Considerações finais}

Se até o primeiro decênio do século passado as escolas fundadas pelos imigrantes germânicos são caracterizadas como alemãs, nas décadas seguintes emergiram condições históricas para uma transformação histórica no plano cultural: daquilo que era entendido como tipicamente germânico para uma identidade teuto-brasileira, híbrida e sincrética. Dentre os fatores geradores de mudanças, temos o clima de nacionalismo que se contrapôs às influências alemãs. Em decorrência, buscou-se incutir a brasilidade e extinguir a germanidade, o que produziu um cimento cultural nas condutas individuais e coletivas, assim como nos arranjos e modos de ação institucionais.

Por conseguinte, o ambiente cultural passou a ser teuto-brasileiro, o que constatamos nos documentos analisados, os quais demonstram que o aparecimento de escolas no cenário da imigração alemã em Santa Catarina, ao longo da primeira metade do século passado, incorporou as marcas de uma composição sincrética. O processo de instituição dessas escolas foi instruído por fatores econômicos determinados pela presença no meio rural, pelo bilinguismo e ainda pelas relações entre as instituições religiosas católicas e protestantes e as instituições escolares. Portanto, a escola teuto-brasileira surgiu como fruto de relações harmônicas ou conflituosas com o ambiente brasileiro. Nos termos de Schaden (1966: 70), esses aspectos podem ser compreendidos considerando-se o «ideal da homogeneidade cultural do país», presente desde a época da chegada dos primeiros imigrantes alemães, assim como as posteriores «[...] medidas governamentais de nacionalização referentes ao idioma» surgidas por volta da primeira Guerra Mundial.

Embora se admitindo a existência de uma primordial «escola alemã», vimos que por meio de um processo que conjugou forças culturais, mas também políticas, aquelas escolas estrangeiras, vistas como não integradas ao sistema nacional, incorporaram transformações infraestruturais e de cunho didático-pedagógico, as quais foram relativizando a força da primordial cultura germânica, permitindo que ingredientes de brasilidade fossem acrescentados. Ou seja, foi no contato com o diferente que a matriz germânica se afirmou, mas também que absorveu elementos de transformação cultural, sendo relativizada, penetrada e clivada. A 
resultante teuto-brasileira é, neste sentido, fruto das relações entre os dados germânicos originais - o Deutschtum - e as componentes culturais brasileiras.

As transformações que analisamos indicam que a condição de teuto-brasileiro aproximou as comunidades de reivindicar direitos. Uma vez permeável ao que era tipicamente nacional, o sujeito teuto-brasileiro se tornou, também, mais facilmente assimilável. Para Seyferth (1994: 15): "No início do século Xx, as chamadas "colônias alemãs" não estavam assimiladas - inclusive porque o fluxo imigratório não havia terminado -, mas, paulatinamente, iam se tornando teuto-brasileiras».

Inevitável, portanto, que as escolas entranhadas no ambiente colonial fossem também se metamorfoseando. Nossos achados permitem concordar com as análises do percurso por que passaram escolas fundadas por imigrantes e seus descendentes em Santa Catarina elaboradas por Santos (20I4), as quais mostram que se inicialmente elas foram constituídas como instituições estrangeiras em território brasileiro, ou seja, como escolas alemãs, devido às modificações nos contextos econômicos, políticos e sociais das primeiras décadas do século xx elas incorporaram uma nova perspectiva identitária, que amalgamou àquelas componentes de germanidade elementos culturais de matiz eminentemente brasileiro. Em suas palavras:

Da condição de 'escolas alemãs' de cariz étnico fundado em relações sociais vinculadas à cultura teuto-europeia, [...] foram sendo orientadas a um ensino sob a racionalidade técnica e o ideário governamental de abrasileiramento, que as cunhou mediante uma nova identidade: a teuto-brasileira (Santos, 20I4: 242).

Neste sentido, ratificamos a instituição de escolas primárias teuto-brasileiras rurais nas primeiras décadas do século xx como processo histórico vivo e ativo, que foi incorporando, mas também produzindo, elementos de organização e funcionamento. Pusemos em evidência aquilo que caracterizou as instituições escolares em relação à sua finalidade social e, mais especificamente, quanto ao impacto que tiveram na formação de indivíduos e coletivos. Por conseguinte, entendemos a escola primária teuto-brasileira rural como uma instituição que produziu e se autoelaborou, ao mesmo tempo em que preservou elementos da cultura do entorno. Nas palavras de Seyferth (1994: I4): «A etnicidade teuto-brasileira tem sido reafirmada de diferentes formas ao longo deste século, sempre destacando um modo peculiar, diferente, de ser brasileira».

No âmago de um processo histórico que produziu um rol de transformações, à medida que a escola alemã foi incorporando políticas e práticas pedagógicas pautadas pela realidade educacional e cultural brasileiras, deu origem, forma e cores próprias à escola primária teuto-brasileira rural.

\section{Referências}

Arquivo Histórico Eugênio Victor Schmöckel: Comunidade Santa Cruz, I937, Preto e Branco: Io,I x 6,24 cm. 
Arquivo Privado: Festa de colocação da pedra fundamental da Escola de Rio Paulo, 1928. Preto e Branco: Io x 6,5 cm.

Arquivo Privado: Inanguração da Escola de Rio Paulo em 1928, 1928, Preto e Branco: 9,97 x $6,4 \mathrm{~cm}$.

Arquivo Privado: Caderno, 1946.

Fiori, Neide A.: Aspectos da evolução do ensino público: ensino público e política de assimilação cultural no Estado de Santa Catarina nos períodos Imperial e Republicano, 2. ed. rev. Florianópolis, Ed. da UFSC, I99I.

Hernández Díaz, José M. ${ }^{a}$ : «Etnografía e historia material de la escuela», in Benito, Agustín E. e Hernández Díaz, José M. (coords.): La memoria y el deseo: cultura de la escuela y educación deseada, Valencia, Tirant lo Blanch, 2002, pp. 225-246.

JARAGUÁ do Sul: Statuten der Schulverein Jaraguá no. 99, Jaraguá do Sul, 29 dez. 1915 (manuscrito).

JaRAguá do Sul: Escola Municipal Rui Barbosa. Fórmula n.2 Instituto IBGE Depto. Estadual de Estatística Estado de Santa Catarina, 1944a.

JaRAguÁ do Sul: Escola Isolada Municipal Osvaldo Cruz. Informações referentes a sociedade escolar (antiga escola alemã). Jaraguá do Sul, 25 maio 1944b (impresso).

Jaraguá do Sul: Escola Municipal Rui Barbosa. Termo de visita. Jaraguá do Sul, 25/26 maio I948a (impresso).

Jaraguá do Sul: Escola Municipal Rui Barbosa. Termo de visita. Jaraguá do Sul, 2I ago I948b (impresso).

Jaraguá do Sul: Escola Municipal Rui Barbosa. Termo de visita. Jaraguá do Sul, 25 out. 1949 (impresso).

Jaraguá do Sul: Escola Municipal Rui Barbosa. Termo da $4 .^{a}$ visita durante o ano de r95o. Jaraguá do Sul, 29 nov. 1950 (manuscrito).

Joinville: Estatutos da Sociedade Escolar Catholica de Jaraguá I (No. 84), Joinville, i907. [n. p.] (manuscrito).

Luna, José M. F.: O português na escola alemã de Blumenau: da formação à extinção de uma prática, Itajaí: Ed. da Univali; Blumenau: Edifurb, 2000.

Minha língua: grammatica portuguesa para uso nas escolas allemãs no Brasil - Portugiesisches Sprachbuch für die deutschen Schulen in Brasilien, São Leopoldo, Rotermund, [s. d.].

Museu Municipal Emílio da Silva: Caderno, i93o.

Nosella, Paolo e Buffa, Ester: Instituições escolares: por que e como pesquisar, Campinas, sP, Editora Alínea, 2009.

Rambо, Arthur B.: A Escola comunitária teuto-brasileira católica, São Leopoldo, Ed. Unisinos, I994.

Rambo, Arthur B.: A escola comunitária teuto-brasileira católica: a Associação dos Professores e a Escola Normal, São Leopoldo, Ed. Unisinos, 1996.

Rамво, Arthur B.: «O teuto-brasileiro e sua identidade», in Fiori, Neide Almeida (org.): Etnia e educação: a escola "alemã» do Brasil e estudos congêneres, Florianópolis, Ed. da UFSC; Tubarão: Ed. Unisul, 2003, pp. 63-92.

Santa Catarina: Fórmula n.2 IBGE Depto. Estadual de Estatística Estado de sC, 1944.

SANTA Catarina: Ensino Primário geral - 1945 Informação anual à-cêrca da organização $e$ aproveitamento, 1946.

SAnTos, Ademir V.: "A política educacional nacionalista e o aspecto linguístico na era Vargas: vestígios na escola primária», Revista Brasileira de Estudos Pedagógicos, Brasília, v. 90, n. 225, (maio/ago. 2009), pp. 5II-527.

SANTOS, Ademir V.: «Educação e nacionalismo: configurando a escola primária catarinense na Era Vargas». Revista Brasileira de História da Educação, Maringá, n. 24 (2010), pp. 83-III.

SANTos, Ademir V.: "Educação e colonização no Brasil: as escolas étnicas alemãs», Cadernos de Pesquisa, São Paulo, v. 42, n. I46 (maio/ago. 20I2), pp. 538-56I. 
SANTos, Ademir V.: «As escolas alemãs em Santa Catarina e sua transformação para teutobrasileiras: uma análise histórica», Acta Scientiarum. Education, Maringá, v. 36, n. 2 (julydec., 20I4), pp. 233-242.

SANTOS, Ademir V.: «Zeitgeist ou espírito alemão: etno-história de germanidade e instituição da escola em Santa Catarina», Educação e Pesquisa, São Paulo, v. 4I, n. 2 (abr.-jun., 20I5), pp. 325-340.

Santos, Ademir V. e Cecchetti, Elcio: «A presença de Lutero no Brasil: o poder da fé, a imigração alemã e a educação", Comunicações, v. 25, n. 2 (maio/ago. 20I8), pp. 283-305.

SCHAden, Egon: «Aspectos históricos e sociológicos da escola rural teuto-brasileira», in Colóquio de Estudos Teuto-Brasileiros, I, I963, Porto Alegre. Anais, Porto Alegre, Ufrgs, I966, pp. 65-77.

SEYFERTH, Giralda: Imigração e cultura no Brasil, Brasília, Ed. Universidade de Brasília, I99o.

Seyferth, Giralda: "A identidade teuto-brasileira numa perspectiva histórica», in MaUch, Claudia e Vasconcellos, Maira (orgs.): Os alemães no sul do Brasil: cultura, etnicidade, bistória. Porto Alegre: ULbRA, 1994.

Wiese, Harry: De Neu-Zürich a Presidente Getúlio: uma história de sucesso, 3.ed. Ibirama, Edigrave, 20II. 